\title{
The Association Between Hypoxia Improvement and Electroconvulsive Therapy for Major Depressive Disorder
}

\author{
Zhida Bian (D) ${ }^{1,2, *}$ \\ Hui $\mathrm{Li}^{3,4, *}$ \\ Yanlong Liu $^{5} *$ \\ Yanjun $\mathrm{Cao}^{2}$ \\ Yanxia Kang ${ }^{2}$ \\ Yongjun $\mathrm{Yu}^{2}$ \\ Feng Zhang ${ }^{1,2}$ \\ Cunbao $\mathrm{Li}^{1}$ \\ Yimin Kang' \\ Fan Wang (iD) 2,4
}

'Psychosomatic Medicine Research Division, Inner Mongolia Medical University, Huhhot, OIOI I0, People's Republic of China; ${ }^{2}$ Beijing Hui-Long-Guan Hospital, Peking University, Beijing, 100096, People's Republic of China; ${ }^{3}$ Department of Biomedical Engineering, College of Engineering, Peking University, Beijing, I0087I, People's Republic of China; ${ }^{4}$ Xinjiang Key Laboratory of Neurological Disorder Research, The Second Affiliated Hospital, Urumqi, 830063, People's Republic of China; ${ }^{5}$ School of Mental Health, Wenzhou Medical University, Wenzhou, 325035, People's Republic of China

*These authors contributed equally to this work

Correspondence: Fan Wang Beijing Hui-Long-Guan Hospital, Peking University, Beijing, 100096, People's Republic of China

$\mathrm{Tel}+86$ I0 83024429; +86 99I-4609006

$\mathrm{Fax}+861062716285 ;+86$ 99I-4609100

Email FanWang@bjmu.edu.cn

Yimin Kang

Psychosomatic Medicine Research Division, Inner Mongolia Medical University, Huhhot, OI0I 10, People's Republic of China

Tel/Fax+86 47I-6657548

Email kangym@immu.edu.cn
Background: The occurrence of depression was related with a state of mild hypoxia for a long time. Hypoxia-inducible factor- $2 \alpha$ (HIF-2 $\alpha$ ) modulates the process from acute to chronic hypoxia, consequently regulating changes in inducible nitric oxide synthase (iNOS). Increasing levels of iNOS combined with major depressive disorder (MDD) have been associated with the concentration of interleukin-6 (IL-6) and tumor necrosis factor-alpha (TNF- $\alpha$ ), which increase the severity of depression.

Objective: The aim was to investigate whether depressive symptoms might be improved by regulating HIF- $2 \alpha$ levels to decrease the degree of oxidative stress and inflammation using electroconvulsive therapy (ECT).

Methods: In this observational study, 49 MDD patients were divided into the ECT group $(n=32)$ and control group $(n=17)$. The Hamilton Depression Rating Scale (HAMD) was used to evaluate depressive symptoms of patients at enrollment and after 2 weeks of treatment. The levels of HIF-2 $\alpha$, NOS, IL-6, and TNF- $\alpha$ in plasma were analyzed accordingly.

Results: The total score in each dimension of HAMD decreased more efficiently in the ECT group than in the control group $(p<0.05)$. The plasma levels of IL-6 in the ECT group were notably decreased after the 2 -week treatment $(t=3.596, p=0.001)$. The decreased trend to statistical significance of HIF-2 $\alpha$ was observed after treatment in the ECT group $(p=0.091)$. Conclusion: The present study demonstrated that the therapeutic effects of long-term ECT therapy for MDD may further benefit from and contribute to the improvement of MDDassociated chronic hypoxia.

Keywords: major depressive disorder, modified electroconvulsive therapy, hypoxiainducible factor, neuroinflammation, oxidative stress

\section{Introduction}

Depression is a serious psychiatric illness that was predicted to be the premier burden of disease in the world by 2030. ${ }^{1}$ Hypoxia plays a significant role in the pathogenesis and exacerbation of MDD. Numerous studies ${ }^{2-4}$ suggested that chronic hypoxia contributes to depression; alternatively, the prevalence of depression also causes a state of mild hypoxia for a long time. ${ }^{5}$ When the body is in a state of chronic hypoxia, hypoxiainducible factor (HIFs) participates in the adaptation process of the change of oxygen utilization rate. ${ }^{6}$ Endothelial cells adapt to changes in $\mathrm{O}_{2}$ availability primarily through HIFs whose activity is regulated by their subunits such as HIF- $2 \alpha{ }^{7}$ HIF-2 $\alpha$ controls the process of transition from acute to chronic hypoxia, ${ }^{8}$ and thus modulates the process of oxidative stress and regulates the change of inducible nitric oxide synthase (iNOS). ${ }^{9}$ 
Hypoxic-ischemia results in oxidative stress, followed by cell death and inflammation. ${ }^{10-12}$ Numerous studies have reported that oxidative damage and increasing levels of iNOS in the brain were observed in patients with major depressive disorder (MDD). ${ }^{13}$ Oxidative stress level have been found to be significantly higher in patients with MDD than in the general population. ${ }^{14}$ Increasing levels of iNOS were also associated with higher levels of proinflammatory factors' transcription and concentrations of interleukin-6 (IL-6) and tumor necrosis factor-alpha (TNF$\alpha),{ }^{15}$ causing inflammation and exacerbating depression. ${ }^{16}$ The primary perspective of MDD development has suggested that iNOS-induced neurovascular damage ${ }^{17}$ may lead to excessive diffusion of proinflammatory cytokines into the brain. ${ }^{16}$ The combined effects of oxidative stress and neuroinflammation leads to neuronal cell injuries. On the contrary, administering antioxidant supplements has been found to promote neuroprotection and symptom improvement in patients with MDD. ${ }^{18}$

Electroconvulsive therapy (ECT) is considered the most effective treatment for depression refractory to medication. ${ }^{19}$ ECT can also enhance the therapeutic effects of selective serotonin reuptake inhibitor(SSRI) drugs. ${ }^{20}$ Numerous studies have shown that ECT can potentially improve patients' depressive symptoms by reducing neuroinflammatory responses $;{ }^{21}$ however, identification of the effective mechanisms involved is still inconclusive. Studies have shown that the improvement of depression synchronizes with hypoxia relief. ${ }^{22}$

Therefore, it has been hypothesized that depressive symptoms might be improved by using ECT to regulate HIF-2 $\alpha$ levels and decrease oxidative stress and inflammation. The purpose of this study was to analyze differences in the levels of HIF-2 $\alpha$, NOS, IL-6, and TNF- $\alpha$ in plasma between the ECT group and the control group before and after ECT treatment for MDD. Further, this study also aimed to investigate the neuroimmune mechanisms of ECT treatment for MDD.

\section{Materials and Methods \\ Study Design}

This observational study was approved by the Ethics Committee of the Beijing Huilongguan Hospital (No. 2017-43), and was performed in accordance with the Declaration of Helsinki. Written informed consent was directly acquired from the participants or their corresponding guardians. The study recruited 49 inpatients administered SSRIs and/or ECT at the Beijing Huilongguan Hospital.

\section{Participants}

A total of 49 patients diagnosed with MDD as defined in the Diagnostic and Statistical Manual of Mental Disorders, 4th Edition Text Revision (DSM-IV-TR), were recruited separately by two experienced psychiatrists. Participants were aged between 18-65 years old, and were enrolled using convenience sampling between March 1 and November 30, 2019. According to the enrollment sequence, 32 MDD patients were selected for the experimental group and were administered ECT, whereas the remaining 17 patients formed the control group. Both groups were administered citalopram $40 \mathrm{mg} / \mathrm{d}$ during the observational period, and all complied with the medication regimen.

Sociodemographic data and clinical history of all participants were collected, including age and educational experience. An anesthetist examined the participants' anesthesia fitness according to the Preoperative Risk Criteria of the American Society of Anesthesiologists. Participants were excluded if they self-reported or if their family confirmed medical history of substance abuse or dependence, except nicotine-containing substances. Those who required a different anesthetic scheme, or had serious adverse effects to anesthetics (eg, allergy), were excluded. We also excluded those who: were diagnosed with bipolar disorder or any concomitant mental disorders; were diagnosed with any comorbid medical/surgical diseases; had any implants in the body, such as intracranial electrodes, pacemakers, or clips; or were pregnant.

\section{Electroconvulsive Treatment Procedure}

ECT was administered under general anesthesia 3 times per week, barring weekends, for a total of 7 times during the study. Participants were evoked using bilateral electrical stimulation with a pulse wave (Somatics LLC, Lake Bluff, Ill).

The stimulus intensity was determined using the halfage method, in which the quantity of electricity equals the half of respective participants' ages. ${ }^{23}$ ECT was performed with brief-pulse and constant current (pulse width: $0.5 \mathrm{~ms}$; frequency: $60 \mathrm{~Hz}$; current: $0.9 \mathrm{~A}$ ). It was considered effective when the duration of seizures was at least 25 seconds as per electroencephalography, and at least 20 seconds as per electromyography. Thiopentone $(2.5 \mathrm{mg} / \mathrm{kg})$ was used as the general anesthesia inducer, and suxamethonium 
$(0.8 \mathrm{mg} / \mathrm{kg})$ was administered as a muscle relaxant after induction of anesthesia.

Drug replacement was not performed during ECT treatment. The ECT was stopped if the participants developed any complications, or if they or their caregivers withdrew consent.

\section{Assessment}

The Hamilton Depression Rating Scale (HAMD) was used to evaluate participants at baseline and post-treatment (for the ECT group, after the sixth treatment).

The HAMD-24 includes component 1 (Anxiety, C1), component 2 (Weight, C2), component 3 (Cognitive impairment, C3), component 4 (diurnal variation, C4), component 5 (Retardation, C5), component 6 (Sleep disturbance, C6), and component 7 (Feeling of despair, C7). A global score over 35 indicates severe depression. Owing to instances when the clinical manifestations of patients are sometimes lighter than their actual conditions, it is the actual diagnosis when they were enrolled that is preferentially considered.

\section{Blood Sample Collection and Laboratory Tests}

Peripheral blood was extracted at 7:00 am before the ECT treatment (day 0) and on the day after the sixth ECT session (day 14). The plasma was separated and frozen at $-80^{\circ} \mathrm{C}$ immediately. IL-6, TNF- $\alpha$, and HIF- $2 \alpha$ levels were measured using an enzyme-linked immunosorbent assay (ELISA) kit (Cloud-clone Corp., Katy, TX, USA) according to the manufacturer's instructions. Spectrophotometric measurement was used to assay NOS levels (JianCheng Bioengineering Institute, Nanjing, China).

\section{Statistical Analysis}

All data were expressed as the mean \pm standard deviation. The paired $t$-test was used to assess the differences in continuous variables between pre and post treatment. Student $t$-test was used to assess the differences in demographic and clinical variables between the two groups. The $p$-value were adjusted using the Bonferroni correction, with the new critical p-value after correction being $\alpha / n$ (n $=2$ ). Partial correlation analysis was performed to assess correlations between continuous variables with education as a covariate.

All data were analyzed using the SPSS 22.0 software (Statistical Package for Social Studies, Chicago, IL, USA).
Graphs were plotted using GraphPad Prism 7 (GraphPad Software, Inc. San Diego, CA, USA). All tests were twotailed, and a $p$-value of 0.05 was considered statistically significant.

\section{Results}

Demographic and Clinical Characteristics Compared to the ECT group, the control group had more extensive educational experience (13.65 \pm 2.78 vs $10.94 \pm$ 3.45 years, $p<0.05$ ). No significant differences were found in clinical and demographic characteristics at baseline between the two groups $(p>0.05)$ (Table 1).

\section{Differences in HAMD Scores After Treatment}

Table 2 shows that the total scores and dimensions of HAMD in both groups decreased significantly as compared to the baseline ( $p<0.05$, shown in Figure 1A and B). Of the 32 patients in the ECT group, 29 (91\%) showed a reduction in HAMD scores by at least $50 \%$, whereas only $7(41 \%)$ in the control group reported similar reductions.

Significant differences in total HAMD scores and dimensions, except for $\mathrm{C} 2$, were found between the two groups after treatment $(p<0.05$, shown in Figure 2). Additionally, there were significant differences in HAMD $\mathrm{C} 1, \mathrm{C} 4, \mathrm{C} 6$, and total scores, between the two groups ( $p<$ $0.01, d f=47)$. All the results were calculated using Student $t$-test $(p<0.05, d f=47)$ (Table 2).

\section{Biomarker Analyses}

There were no significant differences in biomarkers at baseline between the two groups. In the ECT group, IL-6

Table I Comparison of Demographic Variables Between ECT Group and Control Group

\begin{tabular}{|c|c|c|c|c|}
\hline \multirow[t]{2}{*}{ Variables } & \multirow{2}{*}{$\begin{array}{c}\text { ECT } \\
\text { Group } \\
\text { (mean } \pm \\
\text { SD) }\end{array}$} & \multirow{2}{*}{$\begin{array}{l}\text { Control } \\
\text { Group } \\
\text { (mean } \pm \\
\text { SD) }\end{array}$} & \multicolumn{2}{|c|}{$\begin{array}{c}\text { Inter- } \\
\text { Group comparison }\end{array}$} \\
\hline & & & $t / Z$ & $p$ \\
\hline Age & $\begin{array}{r}41.47 \\
\pm 12.29\end{array}$ & $\begin{array}{r}33.24 \\
\pm 16.13\end{array}$ & 2.00 & 0.051 \\
\hline Education years & $\begin{array}{r}10.94 \\
\pm 3.45\end{array}$ & $13.65 \pm 2.78$ & -2.79 & $0.008^{*}$ \\
\hline Gender & $\begin{array}{c}1.63 \pm 0 . \\
49\end{array}$ & $1.59 \pm 0.5 \mathrm{I}$ & 0.25 & 0.806 \\
\hline
\end{tabular}

Notes: Student $t$-test were used for inter-group comparisons; ${ }^{*} p<0.05$. 
Table 2 Comparison of Scale Variables Intra- and Inter Groups

\begin{tabular}{|c|c|c|c|c|c|c|c|}
\hline \multirow[t]{2}{*}{ Variables } & & \multirow[t]{2}{*}{$\begin{array}{c}\text { ECT Group(mean } \\
\pm \text { SD) }\end{array}$} & \multirow[t]{2}{*}{$\begin{array}{c}\text { Control Group(mean } \\
\pm \text { SD) }\end{array}$} & \multicolumn{2}{|c|}{$\begin{array}{l}\text { Inter-Group } \\
\text { comparison }^{\text {a }}\end{array}$} & \multicolumn{2}{|c|}{ Intra-Group comparison $^{a}$} \\
\hline & & & & $t / Z$ & $\mathbf{p}$ & $\begin{array}{l}\text { ECT Group (Control } \\
\text { Group) } t / Z\end{array}$ & $\begin{array}{c}\text { PECT } \\
\text { (Pcontrol) }\end{array}$ \\
\hline \multirow[t]{2}{*}{ HAMD CI } & Baseline & $7.75 \pm 3.65$ & $10.00 \pm 4.12$ & -1.97 & 0.055 & \multirow{2}{*}{$10.15(4.63)$} & \multirow{2}{*}{$\begin{array}{l}0.000 * * \\
(0.000 * *)\end{array}$} \\
\hline & $\begin{array}{l}\text { Post- } \\
\text { treatment }\end{array}$ & $2.94 \pm 2.45$ & $5.29 \pm 3.02$ & -2.98 & $0.005 * *$ & & \\
\hline \multirow[t]{2}{*}{ HAMD C2 } & Baseline & $1.25 \pm 0.88$ & $0.77 \pm 0.83$ & 1.87 & 0.067 & \multirow{2}{*}{$6.04(3.40)$} & \multirow{2}{*}{$\begin{array}{l}0.000 * * \\
(0.004 * *)\end{array}$} \\
\hline & $\begin{array}{l}\text { Post- } \\
\text { treatment }\end{array}$ & $0.22 \pm 0.42$ & $0.12 \pm 0.33$ & 0.86 & 0.395 & & \\
\hline \multirow[t]{2}{*}{ HMAD C3 } & Baseline & $7.50 \pm 2.07$ & $8.4 I \pm 4.17$ & -0.84 & 0.411 & \multirow{2}{*}{$10.69(3.30)$} & \multirow{2}{*}{$\begin{array}{l}0.000 * * \\
(0.004 * *)\end{array}$} \\
\hline & $\begin{array}{l}\text { Post- } \\
\text { treatment }\end{array}$ & $1.66 \pm 1.72$ & $4.59 \pm 4.02$ & -2.87 & $0.010^{*}$ & & \\
\hline \multirow[t]{2}{*}{ HAMD C4 } & Baseline & $0.8 I \pm 0.74$ & $1.12 \pm 0.70$ & -1.40 & 0.167 & \multirow{2}{*}{$3.84(1.16)$} & \multirow{2}{*}{$\begin{array}{l}0.00 I^{* *} \\
(0.264)\end{array}$} \\
\hline & $\begin{array}{l}\text { Post- } \\
\text { treatment }\end{array}$ & $0.22 \pm 0.42$ & $0.82 \pm 0.8 \mathrm{I}$ & -2.88 & $0.009 * *$ & & \\
\hline \multirow[t]{2}{*}{ HAMD C5 } & Baseline & $8.66 \pm 1.95$ & $8.65 \pm 2.50$ & 0.01 & 0.989 & \multirow{2}{*}{$11.98(4.90)$} & \multirow[b]{2}{*}{$\begin{array}{l}0.000 * * \\
(0.000 * *)\end{array}$} \\
\hline & $\begin{array}{l}\text { Post- } \\
\text { treatment }\end{array}$ & $3.53 \pm 1.80$ & $5.06 \pm 2.63$ & -2.40 & $0.020^{*}$ & & \\
\hline \multirow[t]{2}{*}{ HAMD C6 } & Baseline & $4.81 \pm 1.69$ & $4.18 \pm 1.74$ & 1.24 & 0.221 & \multirow{2}{*}{$11.93(3.28)$} & \multirow{2}{*}{$\begin{array}{l}0.000 * * \\
(0.005 * *)\end{array}$} \\
\hline & $\begin{array}{l}\text { Post- } \\
\text { treatment }\end{array}$ & $1.09 \pm 1.49$ & $2.47 \pm 1.66$ & -2.96 & $0.005 * *$ & & \\
\hline \multirow[t]{2}{*}{ HAMD C7 } & Baseline & $7.72 \pm 2.30$ & $8.06 \pm 3.29$ & -0.42 & 0.674 & \multirow{2}{*}{$10.66(3.12)$} & \multirow{2}{*}{$\begin{array}{c}0.000 * * \\
(0.007 * *)\end{array}$} \\
\hline & $\begin{array}{l}\text { Post- } \\
\text { treatment }\end{array}$ & $3.06 \pm 1.6 \mathrm{I}$ & $5.4 I \pm 3.48$ & -2.64 & $0.016 *$ & & \\
\hline \multirow{2}{*}{$\begin{array}{l}\text { HAMD } \\
\text { total }\end{array}$} & Baseline & $38.50 \pm 7.44$ & $41.17 \pm 11.40$ & -0.87 & 0.391 & \multirow{2}{*}{ 19.74(5.07) } & \multirow{2}{*}{$\begin{array}{l}0.000 * * \\
(0.000 * *)\end{array}$} \\
\hline & $\begin{array}{l}\text { Post- } \\
\text { treatment }\end{array}$ & $12.72 \pm 7.58$ & $23.76 \pm 12.34$ & -3.37 & $0.003 * *$ & & \\
\hline
\end{tabular}

Notes: HAMD-24, 24-item Hamilton Rating Scale for Depression; pECT, p value of ECT group; pcontrol, p value of control group; a, Student t-test were used for inter-group comparisons; b, Intra-group comparisons were evaluated by paired t-test. ${ }^{*}<<0.05$, ${ }^{* *} \mathrm{p}<0.01$.
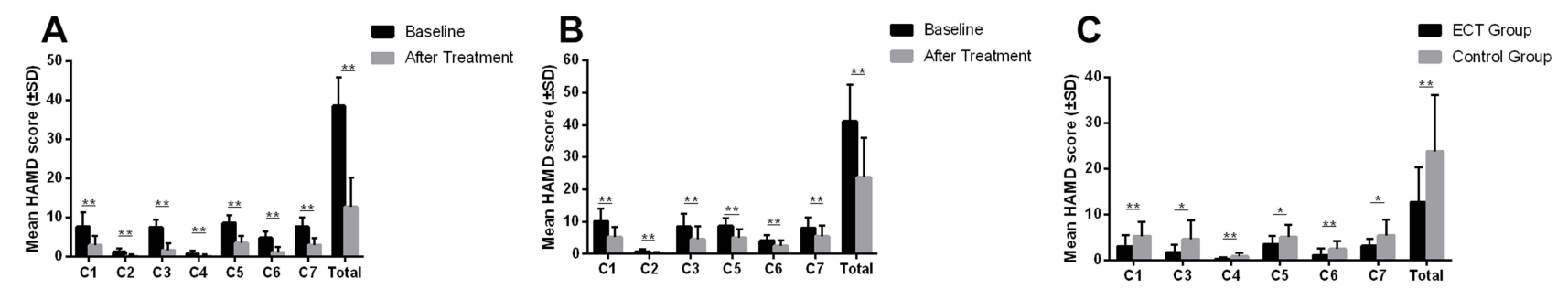

Figure I (A and B) The differences of HAMD variables after two-week treatment compared to baseline in ECT group and control group; (C) The differences of HAMD variables between two groups after two-week treatment; $* p<0.05, *_{p}^{*}<0.01$. 


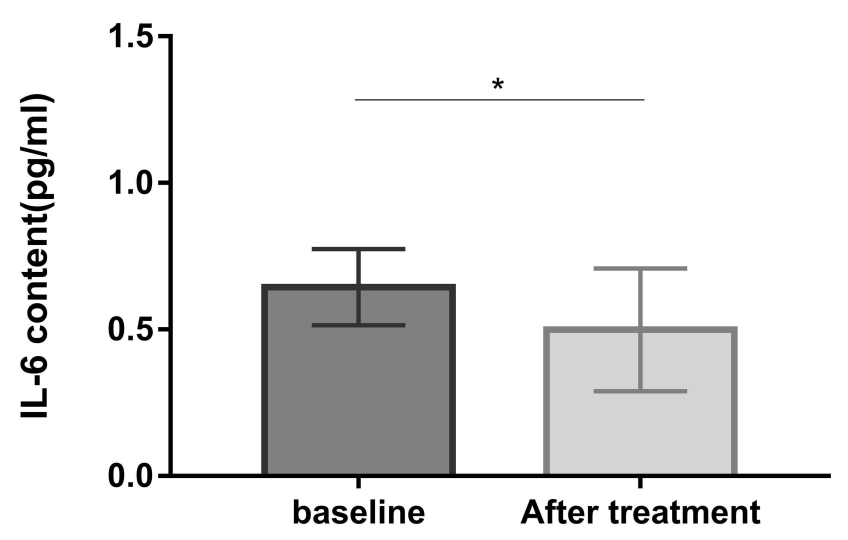

Figure 2 The differences of IL-6 levels after two-week treatment compared to baseline in ECT group; ${ }^{*} p<0.05$.

levels decreased significantly after treatment $(t=3.596$, $p<0.05, d f=47$; shown in Table 3 and Figure 2), as did HIF-2 $\alpha(p=0.091)$. There were no significant differences in biomarkers after treatment in the control group.

Between-group comparisons showed lower concentration of HIF- $2 \alpha$ in the ECT group after treatment, but this difference was not significant $(p>0.05)$. In addition, there were no significant differences in the variables between the two groups after treatment (all $p>0.05$ ).

No correlations were observed between the biomarkers and demographic factors in the two groups after the 2-week treatment, whereas there were no correlations between the differences of biomarkers and the differences of demographic levels in two groups (all $p>0.05$ ). Additionally, there were no correlations between HIF- $2 \alpha$ at baseline and variables including biomarkers and demographics after treatment in both groups. This indicates that HIF- $2 \alpha$ has no significant predictive role in treatment $(p>$ $0.05)$. Furthermore, there were no correlations between the difference of clinical variables and of scale variables after treatment in both groups $(p>0.05)$.

\section{Discussion}

This is the first study that attempted to explore the effect of ECT in the treatment of MDD in the context of hypoxia. The study substantially demonstrates that the plasma HIF- $2 \alpha$ level of patients in ECT group showed a significant tendency to decrease after treatment. The plasma IL-6 levels in the ECT group decreased significantly after the 2-week treatment.

Table 3 Comparison of Biomarkers Between ECT Group and Control Group

\begin{tabular}{|c|c|c|c|c|c|c|c|}
\hline \multirow[t]{2}{*}{ Variables } & & \multirow{2}{*}{$\begin{array}{c}\text { ECT Group } \\
\text { (mean } \pm \text { SD) }\end{array}$} & \multirow{2}{*}{$\begin{array}{l}\text { Control Group } \\
\text { (mean } \pm \text { SD) }\end{array}$} & \multicolumn{4}{|c|}{ Intra-group comparison } \\
\hline & & & & ECT $t / Z$ & $P_{c l}$ & $\begin{array}{c}\text { Control } t / \\
Z\end{array}$ & $P_{c 2}$ \\
\hline \multirow[t]{2}{*}{ IL-6 (pg/mL) } & Baseline & $0.64 \pm 0.13$ & $0.58 \pm 0.12$ & \multirow{2}{*}{3.60} & \multirow{2}{*}{$0.002 * *$} & \multirow{2}{*}{$\mathrm{I} .83$} & \multirow{2}{*}{0.087} \\
\hline & Post-treatment & $0.50 \pm 0.21$ & $0.53 \pm 0.11$ & & & & \\
\hline \multirow[t]{2}{*}{ TNF- $\alpha(p g / m L)$} & Baseline & $0.10 \pm 0.05$ & $0.08 \pm 0.01$ & \multirow{2}{*}{-0.25} & \multirow{2}{*}{0.804} & \multirow{2}{*}{-0.08} & \multirow{2}{*}{0.936} \\
\hline & Post-treatment & $0.10 \pm 0.05$ & $0.08 \pm 0.02$ & & & & \\
\hline \multirow[t]{2}{*}{ HIF- $2 \alpha(\mathrm{ng} / \mathrm{mL})$} & Baseline & $0.36 \pm 0.12$ & $0.34 \pm 0.08$ & \multirow{2}{*}{1.75} & \multirow{2}{*}{0.091} & \multirow{2}{*}{-0.25} & \multirow{2}{*}{0.120} \\
\hline & Post-treatment & $0.31 \pm 0.11$ & $0.36 \pm 0.09$ & & & & \\
\hline \multirow[t]{2}{*}{ iNOS $(\mathrm{U} / \mathrm{mL})$} & Baseline & $13.77 \pm 1.79$ & $14.52 \pm 2.32$ & \multirow{2}{*}{-2.16} & \multirow{2}{*}{0.077} & \multirow{2}{*}{-1.30} & \multirow{2}{*}{0.213} \\
\hline & Post-treatment & $14.88 \pm 2.34$ & $15.07 \pm 2.25$ & & & & \\
\hline \multirow[t]{2}{*}{ cNOS (U/mL) } & Baseline & $7.43 \pm 3.77$ & $8.88 \pm 3.00$ & \multirow{2}{*}{-0.22} & \multirow{2}{*}{0.824} & \multirow{2}{*}{0.38} & \multirow{2}{*}{0.708} \\
\hline & Post-treatment & $7.59 \pm 3.72$ & $8.61 \pm 4.04$ & & & & \\
\hline \multirow[t]{2}{*}{ tNOS (U/mL) } & Baseline & $21.20 \pm 3.62$ & $23.40 \pm 2.77$ & \multirow{2}{*}{-1.78} & \multirow{2}{*}{0.085} & \multirow{2}{*}{-0.55} & \multirow{2}{*}{0.591} \\
\hline & Post-treatment & $22.46 \pm 2.93$ & $23.67 \pm 3.14$ & & & & \\
\hline
\end{tabular}

Notes: All data were reported as mean \pm SD using paired $t$-test. SD, standard deviation; $p c$, after Bonferroni correction; $p c l$, $P$ value of ECT group; $p c 2$, $P$ value of control group.**p $<0.01$.

Abbreviations: IL-6, interleukin-6; TNF- $\alpha$, tumor necrosis factor alpha; HIF-2 $\alpha$, hypoxia-inducible factor-2 $\alpha$; NOS, nitric oxide synthase; tNOS, total NOS; iNOS, inducible NOS; cNOS, constitutive NOS. 
In this study, both groups of participants were administered the SSRI citalopram. HIF-2 $\alpha$ is activated late in the process of hypoxia and mainly regulates the body's adaptation to hypoxia. ${ }^{24}$ Although no studies have reported a direct relationship between HIF- $2 \alpha$ and SSRI analogs, numerous studies have shown that HIF-1 $\alpha$ is extensively involved in the up-regulation of serotonin expression. ${ }^{25}$ Further, the conversion from HIF- $1 \alpha$ to HIF- $2 \alpha$ plays a crucial role in the maintenance of redox homeostasis. ${ }^{26}$ Increased HIF-2 $\alpha$ indicates a progressive and gradual shift from acute hypoxia to chronic hypoxia, ${ }^{26}$ during which serotonin consistently maintains a high expression. Inhibiting the reuptake of serotonin to reduce inflammatory mediators and oxidative factors has been considered as a potential mechanism for treating depression with SSRIs. ${ }^{27,28}$ However, in this study, HIF- $2 \alpha$ and other components from plasma did not change significantly in the control group who were only administered SSRI analogs. Contrastingly, HIF- $2 \alpha$ in the ECT group showed a downward tendency, consistent with our preexperimental hypothesis before the experiment. Additionally, ECT induces membranes to promote the transport of blood and brain substances according to transiently interrupt the blood-brain barrier, and increase cell membrane permeability to relieve the symptoms of depression; but its specific mechanism is still inconclusive. ${ }^{29,30}$ The knockout of the HIF- $2 \alpha$ gene and decreased HIF- $2 \alpha$ levels can both lead to an increase in cell membrane permeability. ${ }^{31}$ In other words, ECT may increase membrane permeability by affecting HIF- $2 \alpha$ levels. This is also clearly related to our preexperimental hypothesis. Although no direct research supports this combination of results, we consider that ECT may treat depression by relieving patients' chronic hypoxia.

ECT is the most effective therapy for drug-refractory depression. ${ }^{19}$ Meta-analyses have found that ECT may produce therapeutic effects through genetic changes ${ }^{32}$ and neurotrophic factors, ${ }^{33}$ but other hypotheses, such as electroencephalography ${ }^{34}$ and neural plasticity, ${ }^{35}$ still remain. Considering the occurrence of mild hypoxia in depression, ${ }^{5}$ and the relationship between hypoxia and oxidative stress, ${ }^{9}$ we consider that improving neuronal hypoxia may be one of the mechanisms of ECT treatment. The purpose of this study was to investigate whether ECT can improve depressive symptoms by regulating hypoxia. Although no significant differences between the ECT and control groups were found in terms of hypoxia-related variables such as HIF-2 $\alpha$, the results did corroborate ECT's established effectiveness in treating depression.
ECT significantly reduced depressive symptoms. After the 2-week treatment, IL-6 levels in the ECT group were significantly lower than during baseline, whereas no such significant difference was found within the control group. ECT can relieve patients' depressive symptoms by reducing the levels of the inflammatory marker IL- $6 .{ }^{36}$ Numerous studies have shown that patients with depression have significantly increased levels of inflammatory markers in the central and peripheral tissues. ${ }^{37}$ In particular, IL-6 is one of the inflammatory markers increasing most discernably in blood samples of patients with depression. Imaging studies have found that ECT may reduce IL-6 levels, reversing the changes in brain structure caused by increased IL-6 levels, thereby relieving symptoms of depression. ${ }^{36}$

This study did not find a direct correlation between HIF- $2 \alpha$, inflammatory factors, and oxidative stress factors in the ECT group. In addition, no significant changes in iNOS were observed, indicating that HIF-2 $\alpha$ may not affect IL-6 levels through the regulation of iNOS, but may do so through other pathways. Further, there were no post-treatment correlations between the differences of clinical variables, including HIF- $2 \alpha$, and the differences of scale variables in either of the group. However, numerous studies have shown that HIF- $2 \alpha$ initiates the transcription of inflammatory factors such as IL-6, and HIF-2 $\alpha$ inhibitors such as HIF- $2 \alpha$ siRNA can effectively inhibit the expression of inflammatory factors. ${ }^{8,38}$

There are some limitations of this study. First, the small sample size may affect the statistical power of the results. Second, although the enrolled participants were categorized according to first-episode depression and chronic depression, several studies have shown that there is no difference in the efficacy of ECT for both categories. Next, it is recommended that future studies should investigate the effect of the addition of antioxidant therapy on MDD patients undergoing ECT therapy.

\section{Conclusion}

We identified one mechanism of ECT to be associated with decreasing neuroinflammation and potentially improving chronic hypoxia. The supplemental application of antioxidant therapy may help enhance the therapeutic effects of ECT; hence, it is recommended that future studies investigate the combined effects of antioxidant therapy and ECT on MDD.

\section{Abbreviations}

MDD, Major depressive disorder; ECT, electroconvulsive therapy; ROS, reactive oxygen species; TNF- $\alpha$, tumor 
necrosis factor alpha; NO, nitric oxide; HPA axis, hypothalamic-pituitary-adrenal axis; NOS, nitric oxide synthase; HIF, hypoxia-inducible factor; SD, standard deviation; tNOS, total NOS; iNOS, inducible NOS; cNOS, constitutive NOS; HAMD, Hamilton Depression Rating Scale.

\section{Access to Data and Data Analysis}

Drs F. Wang had full access to all of the data in the study and take responsibility for the integrity of the data and the accuracy of the data analysis.

\section{Acknowledgments}

We thank professor Qingtao Bian (Beijing Hui-Long-Guan Hospital, Peking University) for his contribution to clinical samples collection. We thank all of the participants for their willingness to participate in the study and the time that they devoted to the study.

\section{Funding}

This work was supported by the following grants: The Technology Support Project of Xinjiang (2017E0267), Natural Science Foundation of Xinjiang Uyghur Autonomous Region (2018D01C228 and 2018D01C239), Tianshan Youth Project-Outstanding Youth Science and Technology Talents of Xinjiang (2017Q007), Natural Science Foundation of China (81560229 and 81760252), Beijing Natural Science Foundation (7152074), The 10th Inner Mongolia Autonomous Region 'Prairie excellence' Project, and the Opening Project of Zhejiang Provincial Top Key Discipline of Pharmaceutical Sciences. The funders had no role in the design and conduct of the study; collection, management, analysis, and interpretation of the data; preparation, review, or approval of the manuscript; and decision to submit the manuscript for publication.

\section{Disclosure}

The authors report no financial interests or potential conflicts of interest.

\section{References}

1. Charlson F, van Ommeren M, Flaxman A, Cornett J, Whiteford H, Saxena S. New WHO prevalence estimates of mental disorders in conflict settings: a systematic review and meta-analysis. Lancet. 2019;394(10194):240-248. doi:10.1016/S0140-6736(19)30934-1

2. Kanekar S, Bogdanova OV, Olson PR, Sung YH, D’Anci KE, Renshaw PF. Hypobaric hypoxia induces depression-like behavior in female Sprague-Dawley rats, but not in males. High Alt Med Biol. 2015;16(1):52-60. doi:10.1089/ham.2014.1070
3. Kious BM, Kondo DG, Renshaw PF. Living high and feeling low: altitude, suicide, and depression. Harv Rev Psychiatry. 2018;26 (2):43-56. doi:10.1097/HRP.0000000000000158

4. Yamagata H, Uchida S, Matsuo K, et al. Identification of commonly altered genes between in major depressive disorder and a mouse model of depression. Sci Rep. 2017;7(1):3044. doi:10.1038/s41598017-03291-x

5. Kushwah N, Jain V, Deep S, Prasad D, Singh SB, Khan N. Neuroprotective role of intermittent hypobaric hypoxia in unpredictable chronic mild stress induced depression in rats. PLoS One. 2016;11(2):e0149309. doi:10.1371/journal.pone.0149309

6. Bartoszewski R, Moszynska A, Serocki M, et al. Primary endothelial cell-specific regulation of hypoxia-inducible factor (HIF)-1 and HIF-2 and their target gene expression profiles during hypoxia. FASEB J. 2019;33(7):7929-7941. doi:10.1096/fj.201802650RR

7. Majmundar AJ, Wong WJ, Simon MC. Hypoxia-inducible factors and the response to hypoxic stress. Mol Cell. 2010;40(2):294-309. doi:10.1016/j.molcel.2010.09.022

8. Bae WJ, Shin MR, Kang SK, et al. HIF-2 inhibition supresses inflammatory responses and osteoclastic differentiation in human periodontal ligament cells. J Cell Biochem. 2015;116(7):1241-1255. doi:10.1002/jcb. 25078

9. Coimbra-Costa D, Alva N, Duran M, Carbonell T, Rama R. Oxidative stress and apoptosis after acute respiratory hypoxia and reoxygenation in rat brain. Redox Biol. 2017;12:216-225. doi:10.1016/j.redox.2017.02.014

10. Dirnagl U, Iadecola C, Moskowitz MA. Pathobiology of ischaemic stroke: an integrated view. Trends Neurosci. 1999;22(9):391-397. doi:10.1016/S0166-2236(99)01401-0

11. Vannucci SJ, Hagberg H. Hypoxia-ischemia in the immature brain. $J$ Exp Biol. 2004;207(18):3149-3154. doi:10.1242/jeb.01064

12. Nzou G, Wicks RT, VanOstrand NR, et al. Multicellular 3D neurovascular unit model for assessing hypoxia and neuroinflammation induced blood-brain barrier dysfunction. Sci Rep. 2020;10(1):9766. doi:10.1038/s41598-020-66487-8

13. Ghasemi M. Nitric oxide: antidepressant mechanisms and inflammation. Adv Pharmacol. 2019;86:121-152.

14. Dhir A, Kulkarni SK. Nitric oxide and major depression. Nitric Oxide. 2011;24(3):125-131. doi:10.1016/j.niox.2011.02.002

15. Brown GC, Neher JJ. Inflammatory neurodegeneration and mechanisms of microglial killing of neurons. Mol Neurobiol. 2010;41(23):242-247. doi:10.1007/s12035-010-8105-9

16. Menard C, Pfau ML, Hodes GE, et al. Social stress induces neurovascular pathology promoting depression. Nat Neurosci. 2017;20 (12):1752-1760. doi:10.1038/s41593-017-0010-3

17. Al-Obaidi MMJ, Desa MNM. Mechanisms of blood brain barrier disruption by different types of bacteria, and bacterial-host interactions facilitate the bacterial pathogen invading the brain. Cell Mol Neurobiol. 2018;38(7):1349-1368. doi:10.1007/s10571-0180609-2

18. Murrough JW, Huryk KM, Mao X, et al. A pilot study of minocycline for the treatment of bipolar depression: effects on cortical glutathione and oxidative stress in vivo. J Affect Disord. 2018;230:56-64. doi:10.1016/j.jad.2017.12.067

19. Leiknes KA, Jarosh-von Schweder L, Hoie B. Contemporary use and practice of electroconvulsive therapy worldwide. Brain Behav. 2012;2(3):283-344. doi:10.1002/brb3.37

20. Haskett RF. Electroconvulsive therapy's mechanism of action: neuroendocrine hypotheses. JECT. 2014;30(2):107-110. doi:10.1097/ YCT.0000000000000143

21. Zheng P, Zeng B, Zhou C, et al. Gut microbiome remodeling induces depressive-like behaviors through a pathway mediated by the host's metabolism. Mol Psychiatry. 2016;21(6):786-796. doi:10.1038/mp.2016.44

22. Vavakova M, Durackova Z, Trebaticka J. Markers of oxidative stress and neuroprogression in depression disorder. Oxid Med Cell Longev. 2015;2015:898393. doi:10.1155/2015/898393 
23. Petrides G, Fink M. The "half-age" stimulation strategy for ECT dosing. Convuls Ther. 1996;12(3):138-146.

24. Gordan JD, Thompson CB, Simon MC. HIF and c-Myc: sibling rivals for control of cancer cell metabolism and proliferation. Cancer Cell. 2007;12(2):108-113. doi:10.1016/j.ccr.2007.07.006

25. Alam T, Maruyama H, Li C, et al. Axotomy-induced HIF-serotonin signalling axis promotes axon regeneration in C. elegans. Nat Commun. 2016;7:10388. doi:10.1038/ncomms 10388

26. Aragones J, Schneider M, Van Geyte K, et al. Deficiency or inhibition of oxygen sensor Phd1 induces hypoxia tolerance by reprogramming basal metabolism. Nat Genet. 2008;40(2):170-180. doi:10.1038/ng.2007.62

27. Lauritsen MP, Loft A, Pinborg A, et al. Individualised gonadotrophin ovulation induction in women with normogonadotrophic anovulatory infertility: a prospective, observational study. Eur J Obstet Gynecol Reprod Biol. 2017;210:76-82. doi:10.1016/j.ejogrb.2016.12.010

28. Galecki P, Mossakowska-Wojcik J, Talarowska M. The anti-inflammatory mechanism of antidepressants - SSRIs, SNRIs. Prog Neuropsychopharmacol Biol Psychiatry. 2018;80(Pt C):291-294. doi:10.1016/j.pnpbp.2017.03.016

29. Singh A, Kar SK. How electroconvulsive therapy works? Understanding the neurobiological mechanisms. Clin Psychopharmacol Neurosci. 2017;15(3):210-221. doi:10.9758/cpn.2017.15.3.210

30. Xiao W, Zhan Q, Ye F, et al. Elevated serum vascular endothelial growth factor in treatment-resistant schizophrenia treated with electroconvulsive therapy: positive association with therapeutic effects. World J Biol Psychiatry. 2019;20(2):150-158. doi:10.1080/ 15622975.2018.1459048

31. Skuli N, Liu L, Runge A, et al. Endothelial deletion of hypoxia-inducible factor-2alpha (HIF-2alpha) alters vascular function and tumor angiogenesis. Blood. 2009;114(2):469-477. doi:10.1182/ blood-2008-12-193581
32. Tang Z, Zhang S, Guo D, Wang H. Association between COMT gene Val108/158Met and antidepressive treatment response: a meta-analysis. Gene. 2020;734:144333. doi:10.1016/j.gene.2020.144333

33. Rocha RB, Dondossola ER, Grande AJ, et al. Increased BDNF levels after electroconvulsive therapy in patients with major depressive disorder: a meta-analysis study. J Psychiatr Res. 2016;83:47-53. doi:10.1016/j.jpsychires.2016.08.004

34. McCormick LM, Yamada T, Yeh M, Brumm MC, Thatcher RW. Antipsychotic effect of electroconvulsive therapy is related to normalization of subgenual cingulate theta activity in psychotic depression. J Psychiatr Res. 2009;43(5):553-560. doi:10.1016/j. jpsychires.2008.08.004

35. Takamiya A, Chung JK, Liang KC, Graff-Guerrero A, Mimura M, Kishimoto T. Effect of electroconvulsive therapy on hippocampal and amygdala volumes: systematic review and meta-analysis. $\mathrm{Br}$ J Psychiatry. 2018;212(1):19-26. doi:10.1192/bjp.2017.11

36. Belge JB, van Diermen L, Sabbe B, et al. Inflammation, hippocampal volume, and therapeutic outcome following electroconvulsive therapy in depressive patients: a pilot study. Neuropsychobiology. 2020;79(3):222-232. doi:10.1159/000506133

37. Krishnadas R, Cavanagh J. Depression: an inflammatory illness? J Neurol Neurosurg Psychiatry. 2012;83(5):495-502. doi:10.1136/ jnnp-2011-301779

38. Wang Q, He Z, Huang M, et al. Vascular niche IL-6 induces alternative macrophage activation in glioblastoma through HIF-2alpha. Nat Commun. 2018;9(1):559. doi:10.1038/s41467-018-03050-0
Neuropsychiatric Disease and Treatment

\section{Publish your work in this journal}

Neuropsychiatric Disease and Treatment is an international, peerreviewed journal of clinical therapeutics and pharmacology focusing on concise rapid reporting of clinical or pre-clinical studies on a range of neuropsychiatric and neurological disorders. This journal is indexed on PubMed Central, the 'PsycINFO' database and CAS, and

\section{Dovepress}

is the official journal of The International Neuropsychiatric Association (INA). The manuscript management system is completely online and includes a very quick and fair peer-review system, which is all easy to use. Visit http://www.dovepress.com/testimonials.php to read real quotes from published authors. 